\title{
Do infiltrating neutrophils contribute to the pathogenesis of indomethacin induced ulceration of the rat gastric antrum?
}

\author{
M A Trevethick, N M Clayton, P Strong, I W Harman
}

\begin{abstract}
The potential involvement of neutrophils in the pathogenesis of indomethacin induced ulceration of the gastric antrum in the re-fed rat was studied. Indomethacin was associated with a time dependent increase in the extent and severity of ulceration, blood neutrophilia, neutrophil infiltration into the gastric antrum, and calcium ionophore induced immunoreactive leukotriene $B_{4}\left(L_{T B}\right)$ release from the antrum ex vivo. Neutrophil infiltration into the antrum was detectable 1 hour after dosing with indomethacin, at which time damage was apparent microscopically but not macroscopically. Thus, cell infiltration may contribute to the development, if not the initiation, of ulceration. Consistent with this suggestion, oral dexamethasone $(5 \mathrm{mg} / \mathrm{kg})$ significantly attenuated indomethacin induced ulceration, the associated neutrophil infiltration, and calcium ionophore induced immunoreactive leukotriene $B_{4}$ release from the gastric antrum and whole blood ex vivo, although the blood neutrophilia was unaffected. These results suggest that indomethacin induced ulceration of the rat gastric antrum may have a dependence on neutrophil infiltration for its pathogenesis.
\end{abstract}

(Gut 1993; 34: 156-160)

The gastric complications associated with chronic use of non-steroidal anti-inflammatory drugs (NSAIDs) pose a major challenge for rheumatologists. ${ }^{12}$ Although NSAID induced gastric ulceration in man usually occurs in the gastric antrum, ${ }^{23}$ most experimental work in vivo has focussed on NSAID induced damage to the fundus. Recently, Wallace et al, stimulated by accumulating evidence that neutrophil accumulation and neutrophil derived factors may be important in several types of gastrointestinal ulceration, published the first reports probing the dependence on neutrophils of indomethacin induced gastric damage. The conclusion of these studies, in both the $\mathrm{rat}^{+}$and rabbit, ${ }^{5}$ was that a significant component of this acute experimental damage was neutrophil dependent.

Some years ago Satoh et $a l^{6}$ described the ability of indomethacin to induce discrete ulcers in the gastric antrum of rats, provided that the animals had been fasted and re-fed before being dosed with indomethacin. Antral ulceration was found to be resistant to treatment with the $\mathrm{H}_{2}$ receptor blocking drug, cimetidine, and was associated with a pronounced infiltration of inflammatory cells (both 'mono- and polymor- phononuclear leukocytes') into the ulcerating tissue. In this study, therefore, we have chosen to investigate the potential role of the neutrophil in the genesis of indomethacin induced ulceration of the gastric antrum in the re-fed rat. In particular, we have studied the relationship between the progression of indomethacin induced ulceration and infiltration of neutrophils and have examined the effects of the antiinflammatory steroid, dexamethasone, on ulceration and cell infiltration.

\section{Methods}

INDUCTION OF ANTRAL ULCERATION

The method used was largely as described by Satoh el al. ${ }^{6}$ In brief, food but not water was withheld from animals for 24 hours. Access was then allowed to food (rat and mouse No 1 maintenance diet (SDS Ltd, Witham, Essex, UK)) for 90 minutes. Indomethacin (usually $60 \mathrm{mg} / \mathrm{kg} ; 1 \mathrm{ml} / 100 \mathrm{~g}$ body weight of a $6 \mathrm{mg} / \mathrm{ml}$ solution in $1 \% \mathrm{NaHCO}_{3}$ in isotonic saline) was then injected subcutaneously. Animals were subsequently allowed continued access to food but water was withdrawn. Control animals received a subcutaneous injection of vehicle ( $1 \%$ $\mathrm{NaHCO}_{3}$ in isotonic saline).

\section{BLOOD NEUTROPHIL COUNTS}

Animals were anaesthetised by inhalation of a mixture of $5 \%$ isofurane/oxygen ( $21 /$ minute) and nitrous oxide ( $11 /$ minute), before and $1-6$ hours after dosing with indomethacin or vehicle. Once adequate anaesthesia had been achieved, 2\% isofurane was used for maintenance. The animal's thorax was then opened and approximately $2 \mathrm{ml}$ of blood were withdrawn by cardiac puncture (using a 21 gauge butterfly needle) and added to vials containing EDTA as an anticoagulant. Blood smears were prepared, stained with DIF QUIK (Travenol Labs, UK), and then examined microscopically. In addition, a blood cell count was performed using a Cell Analyser CA480 (V A Howe Ltd, UK).

\section{ASSESSMENT OF GASTRIC DAMAGE}

Once blood had been removed, rats were killed by cervical dislocation. The stomach (with a small amount of duodenum attached) was removed, opened along the greater curvature, and the contents were washed away with saline $(0.9 \%)$. The opened stomach was stapled (mucosal surface uppermost) to card and fixed in $10 \%$ buffered formalin. All subsequent assess- 
ments of gastric damage were undertaken by an observer blinded to the experimental protocol.

The area of macroscopically apparent damage to the antrum was then estimated by overlaying a transparent plastic grid (consisting of $1 \mathrm{~mm}^{2}$ squares). Next the surface area of the whole antrum was estimated, and the percentage of the antral mucosa which had been damaged was calculated. The corpus was also examined for signs of damage.

Four sections of tissue were taken from each fixed antrum for microscopic assessment. The first was taken from tissue abutting the pyloric sphincter, while the fourth was taken at the oesophageal groove. In addition, four samples of tissue were taken from the fundus, two from each side of the antrum. The samples were taken from the longer axis of the glandular stomach which remained after the antrum had been removed. After tissue processing and embedding in paraffin wax, sections were cut and stained with haematoxylin and eosin and examined microscopically (Zeiss Axioscop microscope). For each section, the following parameters were noted:

\section{Gastric damage}

This was classified as follows:

(1) Superficial erosion - damage to the surface epithelium only,

(2) Deep erosion - glandular epithelium still present,

(3) Ulceration - complete loss of the epithelium to the level of the muscularis mucosa.

\section{Extent of mucosal damage}

The length of antral mucosa showing each degree of damage (superficial erosion, deep erosion, ulceration) was measured using a calibrated eyepiece scale for each of the four sections. The percentage of the total mucosal epithelium examined which showed ulceration or deep erosions was then calculated.

\section{Infiltration by inflammatory cells}

The severity of infiltration was assessed subjectively using the following scale: $0=$ no infiltration; $1=$ very mild infiltration; $2=$ mild infiltration; $3=$ moderate infiltration; $4=$ marked infiltration. For each animal, the median value derived from the four slides taken was used for analysis.

Where required, photographs were taken using a Yashica 108 camera and Kodak vericolor III film.

LEUKOTRIENE B $\mathbf{4}$ RELEASE FROM GASTRIC ANTRUM Ulceration was induced with indomethacin using the method outlined above. Immediately before and 1-6 hours after dosing with indomethacin or vehicle, animals were killed by cervical dislocation and the stomachs removed, cut open along the greater curvature, and rinsed with warm $\left(37^{\circ} \mathrm{C}\right)$, oxygenated $(95 \%$ oxygen: $5 \%$ carbon dioxide) Krebs solution. The fundic and antral regions were removed, and the antrum placed in warm $\left(37^{\circ} \mathrm{C}\right)$, oxygenated Krebs until required. When all of the antra had been collected, each was incubated in an aliquot $(5 \mathrm{ml})$ of fresh Krebs solution for 30 minutes at $37^{\circ} \mathrm{C}$ (basal release). Subsequently each tissue was transferred to fresh medium containing $10^{-5}$ M A23187 (calcium ionophore) for a further 30 minutes (at $37^{\circ} \mathrm{C}$; stimulated release). Incubation media were stored frozen $\left(-20^{\circ} \mathrm{C}\right)$ until required for analysis. The antra were blotted dry, weighed, and antral damage was assessed macroscopically (see above). Leukotriene $B_{4}$ released into the incubation fluid was measured by radioimmunoassay (see below), and the results were expressed as $\mathrm{ng}$ released/g wet weight tissue/ 30 minutes.

The effects of the leukotriene synthesis inhibitors $M K 886^{7}$ and $A 64077^{8}$ were assessed in a parallel series of experiments. In these experiments, antra from animals pretreated with indomethacin were incubated with the desired concentration of MK886 or A64077 for 30 minutes in the absence (basal release) and then presence (stimulated release) of A23187, using the method outlined above. Once again the incubation media were stored frozen before radioimmunoassay. Since samples derived from gastrointestinal tissue have been reported to contain a factor(s) that interferes with leukotriene immunoassay, all samples were placed in a boiling water bath for 5 minutes before assay. ${ }^{9}$ Leukotriene release in the presence of A23187+ MK886 or $\mathrm{A64077}$ was expressed as a percentage of that occurring in the presence of calcium ionophore alone.

\section{LEUKOTRIENE. B 4 RELEASE FROM BLOOD}

Blood samples $(0.2 \mathrm{ml})$ were removed by cardiac puncture (see above) and pipetted into Eppendorf tubes containing the calcium ionophore, A23187, and mixed so that the final concentration was $10^{-5} \mathrm{M}$. Samples were incubated at $37^{\circ} \mathrm{C}$ for 30 minutes, and subsequently centrifuged (Eppendorf Microfuge; $13000 \mathrm{rpm}$ for 4 minutes). Plasma $(70 \mu \mathrm{l})$ was then pipetted into absolute ethanol $(280 \mu \mathrm{l})$, thoroughly mixed, and then centrifuged again (Eppendorf Microfuge; $13000 \mathrm{rpm}$ for 4 minutes). Supernatant was then stored at $-20^{\circ} \mathrm{C}$. When required for assay, the ethanol was evaporated using a stream of nitrogen, and the dried sample reconstituted in assay buffer.

RADIOIMMUNOASSAY OF LEUKOTRIENE $\mathbf{B}_{4}$ Leukotriene $\mathrm{B}_{4}$ was assayed using kits (catalogue no TRK 980) supplied by the Radiochemical Centre (Amersham, UK).

\section{EFFECTS OF DEXAMETHASONE}

Rats were fasted and re-fed as described above. One hour after being allowed access to food, animals were dosed orally (using a dosing volume of $0.5 \mathrm{ml} / 100 \mathrm{~g}$ body weight) with $5 \mathrm{mg} / \mathrm{kg}$ dexamethasone or vehicle $(0.5 \%$ methyl cellulose in distilled water). After a further 30 minutes, indomethacin $(60 \mathrm{mg} / \mathrm{kg})$ was administered subcutaneously. Six hours later animals were divided into groups to study either: 


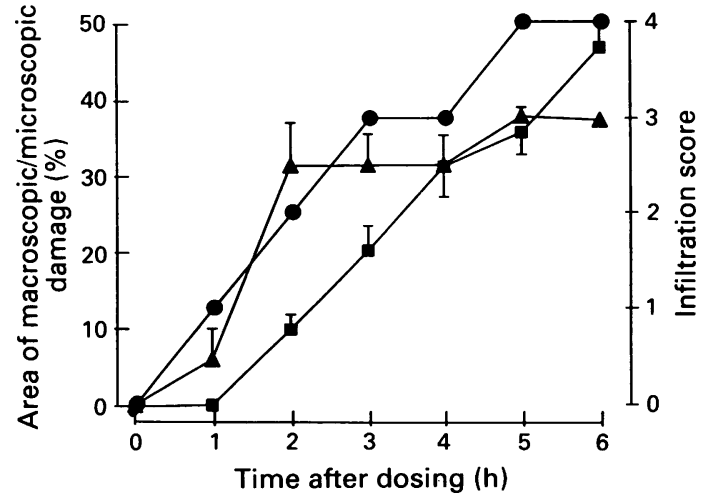

Figure 1: Development of gastric antral ulceration after administration of indomethacin $(60 \mathrm{mg} / \mathrm{kg})$. Results for macroscopic $\left(\square_{n=16}\right)$ and microscopic $(\Delta n=4)$ damage are presented as mean (SEM) where the SEM exceeds the symbol size, whereas infiltration score is shown as the median

$(n=4)$.

(i) The effect of dexamethasone on indomethacin induced macroscopic and microscopic damage, blood levels of neutrophils, release of leukotriene $\mathrm{B}_{4}$ from blood ex vivo and tissue infiltration by neutrophils, or

(ii) The effect of dexamethasone on indomethacin induced increases in leukotriene $B_{4}$ release from the gastric antrum ex vivo.

\section{STATISTICAL ANALYSIS OF DATA}

The data in this publication are mostly presented as the mean (SEM), and where statistical analysis has been employed the Student's $t$ test has been used. However, the extent of inflammatory cell infiltration was graded into five categories. These data therefore are presented as the median value ( \pm quartiles) and statistical significance was assessed by a non-parametric method, the MannWitney U test.

\section{ANIMALS AND COMPOUNDS}

Female, random bred, hooded rats (supplied by Animal Services, Glaxo Group Research, Ware, UK) weighing 70-120 g were used throughout

Figure 2: Histological appearance of an indomethacin induced gastric antral ulcer 6 hours after dosing. (Haematoxylin and eosin stain). this study. The calcium ionophore, A23187 (obtained from the Sigma Chemical Company, Poole, Dorset, UK) was prepared as a $5 \mathrm{mg} / \mathrm{ml}$

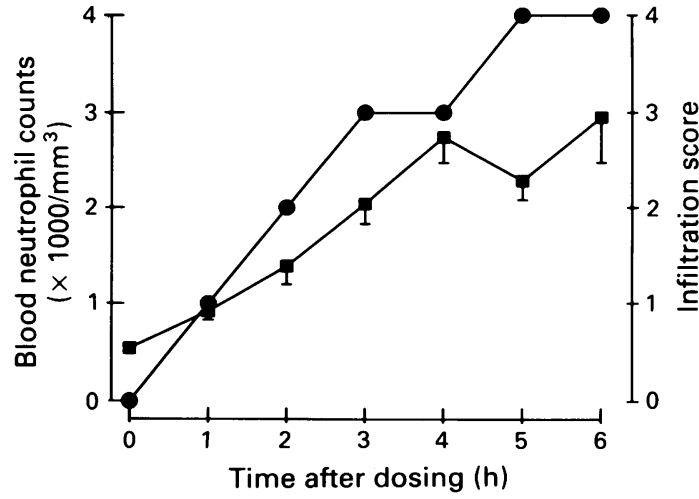

Figure 3: Blood neutrophilia and infiltration in response to indomethacin. Results are shown as the mean (SEM) for neutrophilia $(n=4)$ and the median for infiltration $(\Delta n=4)$.

stock solution in DMSO. Indomethacin and dexamethasone were also obtained from the Sigma Chemical Co. The leukotriene synthesis inhibitors MK886 and A64077 were synthesised in the Medicinal Chemistry Division, Glaxo Group Research.

\section{Results}

\section{INDOMETHACIN INDUCED DAMAGE TO THE} STOMACH

In an initial experiment in which damage was assessed macroscopically, we were able to confirm the findings of Satoh et $a l^{6}$ that $10 \mathrm{mg} / \mathrm{kg}$ subcutaneous indomethacin was the minimum dose required to cause antral damage. For the mechanistic studies described below, however, a dose of $60 \mathrm{mg} / \mathrm{kg}$ was chosen since this produced obvious damage involving $30-40 \%$ of the gastric antrum.

Judged either macro- or microscopically, indomethacin induced a progressive increase over time in the extent of damage to the antral mucosa (Fig 1). Ulceration first became apparent macroscopically as discrete brown/black spots seen 2 hours after dosing with indomethacin. Thereafter, the surface area of the affected mucosa increased. In contrast, small lesions,

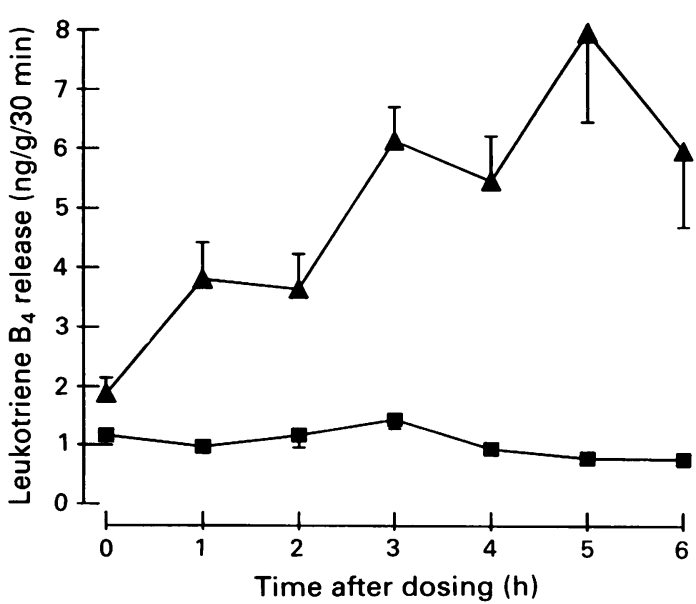

Figure 4: Release of immunoreactive leukotriene $B_{+}$from the gastric antrum ex vivo during indomethacin induced gastric antrum ex vivo during indomethacin induced
ulceration. Results are shown as the mean (SEM) (where ulceration. Results are shown as the mean (SEM) (where
$S E M$ exceeds symbol size; $n=8-16)$. ( $\square$ ) represent basal release, while $(\Delta)$ represent release in the presence of calcium ionophore. 
Effect of dexamethasone ( $5 \mathrm{mg} / \mathrm{kg}$ orally) on indomethacin induced gastric antral ulceration: area of macroscopic and microscopic damage, infiltration by inflammatory cells, blood neutrophilia, and leukotriene $B_{4}\left(\mathrm{LTB}_{4}\right)$ release

\begin{tabular}{|c|c|c|c|c|c|c|}
\hline Treatment & $\begin{array}{l}\% \text { Area } \\
\text { macroscopic } \\
\text { damage }\end{array}$ & $\begin{array}{l}\% \text { Area } \\
\text { microscopic } \\
\text { damage }\end{array}$ & $\begin{array}{l}\text { Infiltration } \\
\text { by } \\
\text { inflammatory } \\
\text { cells }\end{array}$ & $\begin{array}{l}\text { Total blood } \\
\text { neutrophils } \\
\left(\times 1000 \mathrm{~mm}^{\mathrm{i}}\right)\end{array}$ & $\begin{array}{l}\text { Blood } \mathrm{LTB}_{+} \\
\text {release } \\
\text { ( } \mathrm{ng} / \mathrm{g} / 30 \mathrm{~min} \\
\mathrm{ml} \text { plasma }\end{array}$ & $\begin{array}{l}\text { Gastric } \\
\text { antral LTB } \\
\text { release } \\
(\mathrm{ng} / \mathrm{g} / 30 \mathrm{~min})\end{array}$ \\
\hline Control & $\begin{array}{c}0 \\
(30)\end{array}$ & $\begin{array}{c}0 \\
(15)\end{array}$ & $\begin{array}{c}0 \\
(15)\end{array}$ & $\begin{array}{c}0 \cdot 7(0 \cdot 1) \\
(15)\end{array}$ & $\begin{array}{l}8 \cdot 8(1 \cdot 2) \\
(15)\end{array}$ & $\begin{array}{l}8 \cdot 6(1 \cdot 4) \\
(15)\end{array}$ \\
\hline Indomethacin & $\begin{array}{l}33 \cdot 4(2 \cdot 9) \\
(30)\end{array}$ & $\begin{array}{l}27 \cdot 5(4 \cdot 5) \\
(15)\end{array}$ & $\begin{array}{l}3 \cdot 0[2 \cdot 5-3 \cdot 2] \\
(15)\end{array}$ & $\begin{array}{l}2 \cdot 2(0 \cdot 1) \\
(15)\end{array}$ & $\begin{array}{l}73 \cdot 9(21 \cdot 3) \\
(15)\end{array}$ & $\begin{array}{l}64 \cdot 6(17 \cdot 8) \\
(15)\end{array}$ \\
\hline $\begin{array}{l}\text { Indomethacin + } \\
\text { dexamethasone }\end{array}$ & $\begin{array}{l}8 \cdot 4(1 \cdot 4)^{\star} \\
(29)^{\prime}\end{array}$ & $\begin{array}{l}9 \cdot 9(1.9)^{\star} \\
(15)^{-1}\end{array}$ & $\underset{(15)}{1 \cdot 7[1 \cdot 0-2 \cdot 0] \dagger}$ & $\begin{array}{l}2 \cdot 6(0 \cdot 2) \\
(15)\end{array}$ & $\begin{array}{l}16 \cdot 4(2 \cdot 5)^{\star} \\
(15)\end{array}$ & $\begin{array}{l}8 \cdot 6(2 \cdot 7)^{\star} \\
(15)\end{array}$ \\
\hline
\end{tabular}

Values are mean (SEM) with number of observations in ( ) except for infiltration score which is expressed as median with upper and lower quartiles [ ]

${ }^{\star} \mathrm{p}<0.05$ compared with indomethacin (Students' unpaired $t$ test).

$t \mathrm{p}<0.05$ compared with indomethacin (Mann-Whitney U test)

confined to the surface mucosa in the main, were detectable microscopically 1 hour after indomethacin. With time, the proportion of antral mucosa affected increased and damage was observed to penetrate to deeper layers, such that 4-6 hours after dosing many lesions had reached the muscularis mucosa. These lesions showed a neutrophil 'plug' at their base (Fig 2). However, even 6 hours after dosing there was no discernible damage to the fundus, judged either macro- or microscopically.

\section{INDOMETHACIN AND NEUTROPHILS}

In vehicle treated animals, lymphocytes were the predominant leukocytes present in blood samples, and their numbers remain essentially constant throughout the experimental period $\left(\sim 2 \cdot 5 \times 10^{3} \quad \mathrm{\mu l}^{-1}\right)$. Indomethacin treatment, however, caused a detectable increase in the number of circulating neutrophils 1 hour after dosing. Neutrophil numbers increased further, reaching a plateau after 4-6 hours (Fig 3), at which point their numbers had increased four to five-fold (versus pretreatment levels). Over the same time course, there was neutrophil infiltration into the ulcerating gastric antrum (Fig 3), but none was detected into the fundus.

\section{INDOMETHACIN AND OTHER HAEMATOLOGICAL PARAMETERS}

Indomethacin had no significant effect on the numbers of circulating red blood cells or on haemoglobin concentration (remaining constant at $\sim 6.6 \times 10^{6}$ cells $\mu^{-1}$ and $\sim 17 \mathrm{~g} \mathrm{dl}^{-1}$ respectively). Platelet numbers were also unaffected during the first five hours after indomethacin, but at 6 hours there was a small, significant $(\mathrm{p}<0.05)$ rise above predose numbers (time $0=0.87 \times 10^{6} \mu \mathrm{l}^{-1} ; 6$ hours post dose $=1.03 \times$ $\left.10^{6} \mu 1^{-1}\right)$.

RELEASE OF LEUKOTRIENE $B_{4}$

Some basal release of immunoreactive leukotriene $\mathrm{B}_{4}$ was apparent from control and indomethacin treated animals, but this was constant throughout the time course of the experiment. In marked contrast, the calcium ionophore, A23187, induced a time dependent increase in release of immunoreactive leukotriene $B_{4}$ from the antra of indomethacin treated animals (Fig 4). That ionophore-induced release was authentic leukotriene $B_{4}$ is strongly suggested by its susceptibility to inhibition by two leukotriene biosynthesis inhibitors, MK886 and A64077. The $\mathrm{EC}_{50}$ values for the two compounds were found to be $1 \cdot 2(0 \cdot 6,2 \cdot 5)$ and $6 \cdot 0(3 \cdot 4,39 \cdot 6) \mu \mathrm{M}$ respectively (geometric means with $95 \%$ confidence intervals; $n=8$ ).

\section{DEXAMETHASONE AND INDOMETHACIN INDUCED ULCERATION}

Dexamethasone significantly inhibited the extent of indomethacin induced gastric antral ulceration (using macro- or microscopic assessment; Table). Inhibition of ulceration was associated with a significant suppression of inflammatory cell infiltration and gastric antral and whole blood leukotriene $\mathbf{B}_{4}$ synthesis. Indomethacin induced blood neutrophilia, however, was unaffected.

\section{Discussion}

Two recent reports have directly implicated leukocytes in the pathogenesis of NSAID induced damage to the gastric fundus. ${ }^{+5}$ The authors based their conclusions on the protective effects of neutropaenia, ${ }^{+}$or a monoclonal antibody inhibiting endothelial cell-leukocyte interactions. ${ }^{5}$ We are aware of no other reports which assess the relationship between leukocyte infiltration and the development of NSAID induced gastric damage. Furthermore, the clinically important site of ulceration with NSAIDs is the gastric antrum,,$^{23}$ although Bjarnason et al have shown that the small intestine may also be a major site of damage after administration of NSAIDs in man. ${ }^{11}$ The objective of the study reported here, therefore, was to assess the relationship between ulceration of, and neutrophil infiltration into, the rat gastric antrum.

The onset of blood neutrophilia and neutrophil infiltration into the gastric antrum were evident one hour after dosing with indomethacin. At this point damage was only detectable microscopically, consisting mainly of superficial lesions to the epithelium. Thus, neutrophil infiltration was an early event, and preceded the appearance of widespread ulceration. Thereafter, a time dependent increase in the number of circulating neutrophils and of infiltration into the antrum was apparent. At these later time points (2-6 hours after indomethacin) the progressive increase in the 
area and severity of ulceration paralleled that of neutrophil infiltration. Furthermore, animals which had been pretreated with indomethacin showed a pattern of inducible leukotriene $B_{4}$ release that clearly paralleled the progressive infiltration of neutrophils into the antrum. This ionophore induced release could be inhibited by the leukotriene synthesis inhibitors MK886 and A64077, implying that it was authentic leukotriene, especially since the $\mathrm{EC}_{50}$ values observed in this study are similar to published data. ${ }^{78}$ Taken together, these results suggest that infiltrating neutrophils may be the source of the ulcerating tissue's enhanced potential to synthesise leukotriene $B_{4}$.

Thus, the histological data, supported by biochemical evidence, suggest that neutrophil infiltration occurs early on in the pathogenesis of ulceration. Consequently, the acute inflammation associated with ulceration may be a mechanism involved in its initiation or development. Our observation that acute treatment with dexamethasone inhibited both ulceration (assessed by either macro- or microscopic criteria), and the associated neutrophil infiltration, is consistent with this hypothesis. Other workers have also shown that corticosteroids will reduce gastrointestinal damage induced by ethanol or indomethacin in the rat. ${ }^{12-14}$ Thus, neutrophil infiltration may contribute to the pathogenesis of gastrointestinal damage induced by a variety of agents, including indomethacin. This activity is in marked contrast with the reported ability of higher doses of dexamethasone to induce gastrointestinal damage. ${ }^{15}$ In other systems dexamethasone has been found to inhibit neutrophil accumulation in response to chemotactic stimuli. ${ }^{16-18}$ Interestingly, we found that dexamethasone inhibited A23187-induced immunoreactive leukotriene $B_{4}$ synthesis by whole blood ex vivo, but not the indomethacin induced blood neutrophilia, implying that inhibition of arachidonic metabolism via 5-lipoxygenase had occurred. Our data do not allow us to determine the mechanism by which dexamethasone inhibited neutrophil infiltration in these experiments, but do suggest that inhibition of the formation of the chemoattractant leukotriene $\mathrm{B}_{4}{ }^{19}$ may be involved. Furthermore, we have previously reported the ability of indomethacin to enhance the release of leukotriene $B_{4}$ from the gastric antrum, ${ }^{20}$ and Wallace $^{21}$ has reported that dexamethasone can decrease gastric leukotriene synthesis in the rat. A number of workers have already suggested that 5-lipoxygenase inhibitors are antiulcerant, ${ }^{22}$ consistent with leukotriene formation playing an important role in this pathology.

Although the mechanisms involved in the initiation of ulceration by indomethacin remain elusive, this study has highlighted the apparent relationship between neutrophil infiltration and ulcer development. These results, together with those of Wallace et $a l,{ }^{+5}$ suggest that experiments using a range of methods to deplete neutrophil numbers and/or inhibit cell function are warranted. At present it seems that there is an association between the appearance of ulceration and the presence of infiltrating neutrophils at the site of damage. Whether the two phenomena are causally related remains to be determined. Clearly this has an important bearing on our understanding of the pathophysiology, and hence treatment, of NSAID induced gastric ulceration. The authors gratefully acknowledge the expert technical assist-
ance of Mr I Sheldon, Mr R Gray and Mrs H Player and assistance with statistical analysis by Ms G Amphlett and Mrs E A Harrison.

1 Ehsanullah RSB, Page MC, Tildesley G, Wood JR. Prevention of gastroduodenal damage induced by non-steroidal antiinflammatory drugs: controlled trial of ranitidine. $B M \mathcal{F}$

2 Roth SH, Bennett RE. Non-steroidal anti-inflammatory drug gastropathy: Recognition and response. Arch Intern Med 1987; 147: 2093-100.

3 Stock K-P, Bach GL. Ulcer healing with ranitidine and antacids despite continued treatment with non-steroidal anti-inflammatory drugs. Z Rheumatol 1988; 47: 177-81.

4 Wallace JL, Keenan CM, Granger DN. Gastric ulceration by non-steroidal anti-inflammatory drugs is a neutrophildependent process. Am $\mathcal{F}$ Physiol 1990; 259: G462-7.

5 Wallace JL, Arfors K-E, McKnight GW. A monoclonal antibody against the CD18 leucocyte adhesion molecule prevents indomethacin-induced gastric damage in the rabbit. Gastroenterology 1991; 100: 878-83.

6 Satoh H, Inada I, Hirate T, Maki Y. Indomethacin produces gastric antral ulcers in the refed rat. Gastroenterology 1981; 81: 719-25.

7 Gillard J, Ford-Hutchinson AW, Chan C, Charleson S, Denis D, Foster A, et al. L-663,536 (MK-886) (3-[1-(4-chlorobenzyl)-3-t-butyl-thio-5-isopropylindol-2-yl]-2,2-dimethylpropanoic acid), a novel, orally active leukotriene biosynthesis inhibitor. Can F Physiol Pharmacol 1989; 67: 456-64.

8 Carter GW, Young PR, Albert DM, Bouska J, Dyer R, Bell $\mathrm{RL}$, et al. 5-lipoxygenase inhibitory activity of Zileuton. f Pharmacol Exp Ther 1991; 256: 929-37.

9 Peskar BM, Lange K, Hoppa W, Peskar BA. Ethanol stimulates formation of leukotriene $B_{4}$ in rat gastric mucosa. Brf Pharmacol 1986; 31: 283-94.

10 Bjarnasson I, Zanelli G, Smith T, Prouse P, Williams P, Smethurst $\mathrm{P}$, et al. Non steroidal anti-inflammatory druginduced intestinal inflammation in humans. Gastroenterology 1987; 93: 480-9.

11 Bjarnasson I, Williams P, Smethurst P, Peters TJ, Levi AJ. The effect of non-steroidal anti-inflammatory drugs and prostaglandins on the permeability of the human smal bowel. Gut 1986; 27: 1292-7.

12 Wallace JL, Keenan CM, Cucala M, Mugridge KG, Parente L. Mechanisms underlying the protective effects of intereukin 1 in experimental nonsteroidal anti-inflammatory drug gastropathy. Gastroenterology 1992; 102: 1176-85.

13 Derelanko MJ, Long JF. Effect of corticosteroids on indomethacin-induced intestinal ulceration in the rat. $\mathrm{Dig} \mathrm{Dis} \mathrm{Sci}$ 1980; 25: 823-9.

14 Derelanko MJ, Long JF. Influence of prednisolone on ethanol-induced gastric injury in the rat. Dig Dis Sci 1982 27: 149-54.

15 Lancaster C, Robert A. Intestinal lesions produced by prednisolone: prevention (cytoprotection) by 16,16 dimethyl prostaglandin $\mathrm{E}_{2}$. Am $\mathcal{f}$ Physiol 1978; 235: E703-8.

16 Griffiths RJ, Li SW, Wood BE, Blackham A. A comparison of the anti-inflammatory activity of selective 5-lipoxygenase inhibitors with dexamethasone and colchicine in a model of zymosan induced inflammation in the rat knee joint and peritoneal cavity. Agents Actions 1991; 32: 312-20.

17 Tsurufuji S, Kurihara A, Ojima P. Mechanisms of antiinflammatory action of dexamethasone. Blockade by hydrocortisone mesylate and actinomycin D of the inhibitory effect of dexamethasone on lum in matory sites. F Pharmacol Exp Ther 1984; 229: 237-43.

18 Whelan CJ. Species differences in the anti-inflammatory potency of dexamethasone. Brf Pharmacol 1989; 97: 427P.

19 Ford-Hutchinson AW, Bray MA, Doig MV, Shipley ME Smith MJH. Leukotriene $\mathrm{B}_{4}$, a potent chemokinetic and aggregatory substance released from polymorphonuclear leukocytes. Nature 1980; 286: 264-5

20 Clayton NM, Trevethick MA, Strong P. Eicosanoid release from the antral and corpus regions of the rat stomach BrF Pharmacol 1991; 102: 362P.

21 Wallace JL. Glucocorticoid-induced gastric mucosal damage: inhibition of leukotriene but not prostaglandin'biosynthesis Prostaglandins 1987; 34: 311-23.

22 Rainsford KD. The effects of 5-lipoxygenase inhibitors and leukotrięne antagonists on the development of gastric lesion induced by non-steroidal anti-inflammatory drugs in mice. Agents Actions 1987; 21 : 316-9. 